\title{
The histogenesis of Ewing Sarcoma
}

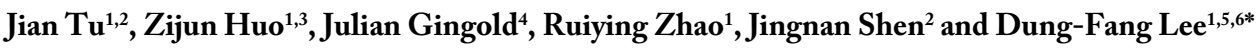 \\ ${ }^{1}$ Department of Integrative Biology and Pharmacology, McGovern Medical School, The University of Texas Health Science Center at Houston, Houston, TX \\ 77030, USA \\ ${ }^{2}$ Department of Musculoskeletal Oncology, The First Affiliated Hospital of Sun Yat-sen University, Guangzhou, China \\ ${ }^{3}$ Department of Endocrinology, The First Affiliated Hospital of Sun Yat-sen University, Guangzhou, China \\ ${ }^{4}$ Women's Health Institute, Cleveland Clinic Foundation, Cleveland, OH 44195, USA \\ ${ }^{5}$ The University of Texas Graduate School of Biomedical Sciences at Houston, Houston, TX 77030, USA \\ ${ }^{6}$ Center for Stem Cell and Regenerative Medicine, The Brown Foundation Institute of Molecular Medicine for the Prevention of Human Diseases, The University \\ of Texas Health Science Center at Houston, Houston, TX 77030, USA
}

Ewing Sarcoma is the second most frequent malignant bone tumor in adolescents and young adults. The majority of Ewing sarcoma arises in the bone, but $15-20 \%$ of Ewing sarcoma originates in the soft tissue surrounding bones $[1,2]$.

Chromosomal translocation is a hallmark of Ewing Sarcoma and has long been considered the primary cause in its development. Around $85 \%$ of Ewing sarcoma harbors a $\mathrm{t}(11: 22)(\mathrm{q} 24: \mathrm{q} 12)$ translocation resulting in the fusion of the $\mathrm{N}$-terminal portion of the EWS gene with the C-terminal portion of the FLI1 gene, one of five ETS family genes [3]. The EWS-FLI1 fusion gene behaves as an aberrant transcription factor to induce or suppress a number of genes modulating transformation, differentiation, cell growth and signal transduction [4,5]. Through direct interactions with RNA processing proteins, EWS-FLI1 also regulates alternative splicing of RNA to impact diverse oncogenic cellular processes (e.g., favoring expression of a TERT isoform with enhanced telomerase activity) [6].

Unlike other sarcomas, such as osteosarcoma and fibrosarcoma, which present some lineage-specific differentiation, Ewing sarcoma is histologically classified as composed of uniformly undifferentiated small round basophilic cells. However, the specific cell type from which Ewing sarcoma is one of the biggest medical mysteries of our time and still under debate. When first reported by James Ewing, in his first reports on the tumor in 1921, proposed an endothelial origin for the sarcoma on the basis of its cellular morphology and the rareness of stroma [7]. In 1971 a myelogenous origin of Ewing sarcoma was proposed given ultrastructural features resembling developing myelocytes [8]. Since then, several hypotheses regarding the histogenesis of Ewing sarcoma have been advanced, with neural crest cells and mesenchymal stem cells receiving the most attention as the putative cells of origin.

The hypothesis of neural crest origin is supported by several lines of evidence. Observational studies reveal that various neural lineage markers, such as neuron-specific enolase and S-100, associated with the neuroectodemal linage are expressed in Ewing sarcoma [9]. Ultrastructural features, such as neurosecretory granules, have been observed with electron microscopy in some Ewing sarcomas [10]. The genome expression profile of Ewing sarcoma is more similar to that of neural crest stem cells than other cell types such as mesenchymal stem cells [11]. A spectrum of neural crest developmental genes is significantly upregulated by ectopic expression of the EWS-FLI1 chimeric protein in a rhabdomyosarcoma cell line, driving the cells to become less differentiated and develop the observed phenotype of Ewing sarcoma [12]. In addition, Ewing sarcoma cell lines undergo neural differentiation upon treatment with various differentiationinducing agents [13].

On the other hand, there is a growing body of evidence supporting a mesenchymal stem cell origin of Ewing sarcoma. CD99 is a relatively specific marker of Ewing sarcoma and is detected at low levels in mesenchymal stem cells and upregulated by EWS-FLI1 [14]. When the EWS-FLI1 fusion protein is expressed in marrow-derived stromal cells, it represses both osteogenic and adipogenic differentiation of bone marrow stromal cells [15]. Ectopic EWS-FLI1 expression in murine primary bone marrow-derived mesenchymal stem cells leads to cell transformation and engraftment of Ewing sarcoma-like tumors in vivo $[16,17]$. These engineered tumors have a similar cellular morphology and express similar cell surface markers to Ewing sarcoma. The knockdown of EWS-FLI1 expression in Ewing Sarcoma results in convergence of the tumor gene expression profiles to that of mesenchymal stem cells [18]. Furthermore, the core EWS-FLI1 transcriptional signature, identified across multiple model system through comparative analysis, shared some characteristics with published mesenchymal stem cell data [19].

To our knowledge, all attempts to identify the Ewing sarcoma cell of origin have relied on the overexpression of EWS-FLI1 in various progenitor cells. EWS-FLI1 expression in these model systems may drive pathology across a number of cell types even if Ewing Sarcoma does not typically arise from these cell types. Distinct cellular phenotypes of Ewing sarcoma may be the result of the relative expression of EWSFLI1 rather than a reflection of the cell of origin. Current advances to generate chromosome fusions by CRISPR/Cas9 methodology may provide a new approach to answer this mystery [20,21].

\section{Acknowledgement}

Both Jian Tu and Zijun Huo are supported by the Ke Lin Program

Correspondence to: Dung-Fang Lee, Department of Integrative Biology and Pharmacology, McGovern Medical School, The University of Texas Health Science Center at Houston, Houston, TX 77030, USA, Tel: 7135006132; Fax: 7135007456; E-mail: dung-fang.lee@uth.tmc.edu

Received: January 11, 2017; Accepted: February 04, 2017; Published: February 07,2017 
of the First Affiliated Hospital of Sun Yat-sen University. D.-F.L. is the CPRIT scholar in Cancer Research and supported by NIH Pathway to Independence Award R00 CA181496 and CPRIT Award RR160019.

\section{References}

1. Arndt CA, Crist WM (1999) Common musculoskeletal tumors of childhood and adolescence. $N$ Engl J Med 341: 342-352. [Crossref]

2. Paulussen M, Fröhlich B, Jürgens H (2001) Ewing tumour: incidence, prognosis and treatment options. Paediatr Drugs 3: 899-913. [Crossref]

3. Delattre O, Zucman J, Plougastel B, Desmaze C, Melot T, et al. (1992) Gene fusion with an ETS DNA-binding domain caused by chromosome translocation in human tumours. Nature 359: 162-165.

4. Janknecht R (2005) EWS-ETS oncoproteins: the linchpins of Ewing tumors. Gene 363: 1-14. [Crossref]

5. Riggi N, Knoechel B, Gillespie SM, Rheinbay E, Boulay G, et al. (2014) EWS-FLI1 utilizes divergent chromatin remodeling mechanisms to directly activate or repress enhancer elements in Ewing sarcoma. Cancer Cell 26: 668-681. [Crossref]

6. Selvanathan SP, Graham GT, Erkizan HV, Dirksen U, Natarajan TG, et al. (2015) Oncogenic fusion protein EWS-FLI1 is a network hub that regulates alternative splicing. Proc Natl Acad Sci USA 112: E1307-E1316. [Crossref]

7. Ewing J (1921) Diffuse endothelioma of bone. Proc NY Pathol Soc 21: 17-24

8. Kadin ME, Bensch KG (1971) On the origin of Ewing's tumor. Cancer 27: 257-273. [Crossref]

9. Franchi A, Pasquinelli G, Cenacchi G, Della Rocca C, Gambini C, et al. (2001) Immunohistochemical and ultrastructural investigation of neural differentiation in Ewing sarcoma/PNET of bone and soft tissues. Ultrastruct Pathol 25: 219-225. [Crossref]

10. Suh CH, Ordóñez NG, Hicks J, Mackay B (2002) Ultrastructure of the Ewing's sarcoma family of tumors. Ultrastruct Pathol 26: 67-76. [Crossref]
11. von Levetzow C, Jiang X, Gwye Y, von Levetzow G, Hung L, et al. (2011) Modelling initiation of Ewing sarcoma in human neural crest cells. PLoS One 6: e19305. [Crossref]

12. Hu-Lieskovan S, Zhang J, Wu L, Shimada H, Schofield DE, et al. (2005) EWS-FLI1 fusion protein up-regulates critical genes in neural crest development and is responsible for the observed phenotype of Ewing's family of tumors. Cancer Research 65: 46334644 .

13. Cavazzana AO, Miser JS, Jefferson J, Triche TJ (1987) Experimental evidence for a neural origin of Ewing's sarcoma of bone. Am J Pathol 127: 507-518. [Crossref]

14. Riggi N, Suva ML, Suva D, Cironi L, Provero P, et al. (2008) EWS-FLI-1 expression triggers a Ewing's sarcoma initiation program in primary human mesenchymal stem cells. Cancer Research 68: 2176-2185.

15. Torchia EC, Jaishankar S, Baker SJ (2003) Ewing tumor fusion proteins block the differentiation of pluripotent marrow stromal cells. Cancer Research 63: 3464-3468.

16. Castillero-Trejo Y, Eliazer S, Xiang L, Richardson JA, Ilaria RL Jr (2005) Expression of the EWS/FLI-1 oncogene in murine primary bone-derived cells Results in EWS FLI-1-dependent, ewing sarcoma-like tumors. Cancer Research 65: 8698-8705.

17. Riggi N, Cironi L, Provero P, Suva ML, Kaloulis K, et al. (2005) Development of Ewing's sarcoma from primary bone marrow-derived mesenchymal progenitor cells. Cancer Research 65: 11459-11468.

18. Tirode F, Laud-Duval K, Prieur A, Delorme B, Charbord P, et al. (2007) Mesenchymal stem cell features of Ewing tumors. Cancer Cell 11: 421-429. [Crossref]

19. Hancock JD, Lessnick SL (2008) A transcriptional profiling meta-analysis reveals a core EWS-FLI gene expression signature. Cell Cycle 7: 250-256.

20. Torres R, Martin MC, Garcia A, Cigudosa JC, Ramirez JC, et al. (2014) Engineering human tumour-associated chromosomal translocations with the RNA-guided CRISPRCas9 system. Nature Communications 5: 3964.

21. Lekomtsev S, Aligianni S, Lapao A, Burckstummer T (2016) Efficient generation and reversion of chromosomal translocations using CRISPR/Cas technology. BMC Genomics 17: 739

Copyright: (C2017 Tu J. This is an open-access article distributed under the terms of the Creative Commons Attribution License, which permits unrestricted use, distribution, and reproduction in any medium, provided the original author and source are credited. 